\title{
APUNTES PARA UNA HISTORIA DEL CRISTIANISMO EN LA NUEVA ESPAÑA A TRAVÉS DE LA LITERATURA Y LA ACTIVIDAD EDUCATIVA FEMENINA
}

\author{
POR \\ María Antonia Bel Bravo \\ Universidad de Jaén
}

\section{RESUMEN}

Los escritos, principalmente femeninos, que he estudiado para este trabajo, no sólo señalan la importancia de la fe cristiana como elemento central en la constitución de la Nueva España, sino que apuntan a las mujeres como importantes transmisoras de esa fe, que implica, según ellas, una forma de vida llena de valores, trasmitidos a través de la familia y las distintas instituciones (colegios, conventos y beaterios).

Palabras Clave: Escritos Femeninos, Nueva España, Colegios, Conventos y Beaterios

\section{ABSTRACT}

The written documents - mainly feminine- which I have studied for this article, not only highlight the important of the Christian Faith as an essential element in the creation of The New Spain, but they also present women as important transmitters of this faith. The Christian Faith according to them, implies a life style full of values, which have been passed on through the family and different institutions (schools, convents, etc.).

KEY WORDS: Written documents, The New Spain, Schools, Convents, beaterios 


\section{INTRODUCCIÓN}

Es más abundante la literatura masculina acerca de los españoles en América, pero es también innegable que, a pesar de su escasez, el conocimiento de la cultura femenina en la Nueva España nos da una visión muy profunda, incluso a veces más real de la historia de aquellas tierras, porque las mujeres en sus escritos descienden pormenorizadamente a los aspectos cotidianos y concretos de la existencia ${ }^{1}$. A través de sus obras, por escasas que sean, y de su actividad educativa, se percibe claramente no sólo cómo se pensaba, sino también cómo se vivía en aquellas zonas recién conquistadas y, a partir de ahí, la cultura y la civilización cobran toda su validez porque son realidad vivida, con la fe en primer término. En este sentido, ha sido fundamental para nuestro estudio la edición facsímil que realizó Josefina Muriel de Las indias caciques de Corpus Christi, pues contiene textos de algunas religiosas que profesaron en aquel convento y decidieron dejar por escrito su vida y experiencias, en concreto lo que significó para ellas ser educadas en el cristianismo. Esta edición apenas tiene una breve introducción de carácter general y ningún estudio crítico sobre los textos concretos de las religiosas.

La obra de Vitoria es también importante para nuestro trabajo. El tema que más le preocupó fue conciliar el plan de Dios con los méritos de la persona. No podía creer que los hombres, ni siquiera algunos de ellos, fuesen malos porque la Providencia los hubiera predestinado a la maldad y, a tenor de esta opinión, desarrolló la doctrina de la Gracia. Como sabemos, algunos discípulos y colegas suyos la llevaron al concilio de Trento, donde la hicieron prevalecer. Salvaron con ello la creencia del hombre en la eficacia de su voluntad y de sus méritos. Otros discípulos la difundieron en el Consejo de Indias, e inspiraron en ella la legislación de las tierras de América, que cambió la conquista del Nuevo Mundo en empresa evangélica, y facilitó la incorporación a la Cristiandad de aquellas razas, a las que llamaban los Reyes de Castilla «nuestros amigos los indios».

De la posibilidad de salvación se deduce — en la época que estudiamos — la de progreso y perfeccionamiento. Decir en lo teológico que todos los hombres pueden salvarse, es afirmar en lo ético que deben mejorar, y en lo político que pueden progresar. Es ya comprometerse a no estorbar el mejoramiento de sus condiciones de vida y aun a favorecerlo en lo posible. Aquellos españoles consideraban a todos los hombres como hermanos, aunque distinguían los hermanos mayores de los menores, porque el español nunca identificó diferencia con desigualdad ${ }^{2}$.

1 Véase Josefina Muriel, Las indias caciques de Corpus Christi, México, UNAM, 2001, p. 355.

2 Véase esta idea muy desarrollada en R. MAEzTu, Defensa de la Hispanidad, Madrid, Rialp, 2000 , pp. 72 y ss.

Hispania Sacra, Missionalia hispanica, 58

117, enero-junio 2006, 329-353, ISSN: 0018-215-X 
Es verdad que los abusos fueron muchos y grandes, pero ninguna legislación colonial extranjera es comparable a las Leyes de Indias. Por ellas se prohibió la esclavitud, se proclamó la libertad de los indios, se les prohibió hacerse la guerra, se les brindó la amistad de los españoles, se reglamentó el régimen de Encomiendas para castigar los abusos de los encomenderos, se instituyó la instrucción y adoctrinamiento de los indios como principal fin de los Reyes de España, se prescribió que las conversiones fueran voluntarias y se transformó la conquista de América en difusión del espíritu cristiano ${ }^{3}$.

«Asimismo se les iba preparando (a los indios) a su autosostenimiento: Se enseñaba no sólo la doctrina cristiana y la vida moral y honesta sino también los oficios y artes manuales. De allí salían diestros los nativos como alarifes, carpinteros, doradores, zapateros, sastres, músicos, herreros, labradores, pescadores de ríos, etc. Los beneficiados eran los antiguos indómitos mobimas, churimanas, cayubas, guarayos, tapacuras y baures» ${ }^{4}$.

\section{LA CONQUISTA DE AMÉRICA Y EL CRISTIANISMO}

La Evangelización americana, al igual que la filipina, ofrece una estructura y unas características generales que le son propias dentro del marco histórico de las misiones católicas. Ambas facetas se derivan de tres factores fundamentales, consistentes en el especialísimo papel que la Corona española desempeñó en el proceso evangelizador, en las, también especialísimas, circunstancias en las que se desarrolló ese mismo proceso y en las particularidades que ofreció el mundo americano, sobre todo el de las sociedades indígenas prehispánicas.

Las relaciones de la Corona española con la evangelización del Nuevo Mundo arrancan, como sabemos, de la Bula Inter Coetera de 3 de mayo de 1493, por la que el papa Alejandro VI, tras recoger el deseo y la promesa expresados por los Reyes Católicos en este sentido, les impone la obligación de enviar a las islas y tierras nuevas descubiertas «varones probos, temerosos de Dios, doctos, instruidos y experimentados», para que convirtieran al cristianismo a los indígenas recién conocidos.

Este precepto evangelizador, impuesto a los reyes españoles, era un requisito conforme a la tradición bajomedieval reflejada en los casos de las Canarias y de las exploraciones portuguesas en el litoral occidental africano. Entraña, en cambio, la novedad de que confía expresamente a la Corona Española el derecho y la obligación de enviar misioneros a América, a diferencia de los documentos pontificios anteriores, en los que no se especifica cómo se debería reali-

\footnotetext{
${ }^{3}$ Ibid.

4 A. Nieto Vélez, La primera evangelización en el Perú, Madrid, 1992, p. 204.
} 
zar la cristianización de las tierras que se descubrieren u ocuparen. A esta inicial obligación, restringida al envío de un personal misionero que en principio no era incumbencia de la Corona, se le fueron añadiendo paulatinamente el derecho y las obligaciones anejos a los sistemas de Patronato Real, del Vicariato Regio y del Regalismo borbónico para que la Corona terminara asumiendo prácticamente todas las facultades y deberes exigidos para la propagación del Evangelio.

En este contexto, el papel de la mujer en América va a tener una importancia singular. Ella es la sintetizadora de dos culturas diferentes, ambas con raíces profundas en sus propias tradiciones, pues como consecuencia del choque étnico y cultural, las mujeres adquirieron importancia como refundidoras de viejas tradiciones e impulsoras de novedades generadas por los problemas que planteaba la vida cotidiana. Las indígenas conservaron hábitos y culturas domésticas prehispánicas, como ha señalado una de las pioneras en estas investigaciones ${ }^{5} \mathrm{y}$ las españolas aportaron sus propias costumbres. Unas y otras tradiciones impregnaron la vida de las tierras americanas de un peculiar carácter mestizo, muy diferente de cuanto los españoles habían dejado al otro lado del océano. El habla popular, el vestido, la alimentación, algunas prácticas curativas y el orden doméstico-familiar mostraban claros rasgos de su raigambre americana. Sin embargo, cuestiones que parecen únicamente relacionadas con el marco familiar se van a proyectar, a través de la mujer, a toda la sociedad.

Como señala Josefina Muriel, «aunque las mujeres no fueron quienes marcaron los lineamientos básicos del pensamiento novohispano, ni ocuparon los puestos públicos ni intervinieron directamente en la política, fueron las activas transmisoras de los valores culturales que constituyeron su mundo, esos que todavía llegan a nosotros tan hondamente como penetran en el alma las aguas del bautismo» 6 .

¿Por qué? Porque en las sociedades preindustriales la familia era una manera de subsistir; sus formas predominaban en las estructuras organizativas artesanas y empresariales, prevalecían el taller familiar y el trabajo doméstico, entre otras cosas porque la propia economía tampoco exigía más. El traspaso de los bienes se llevaba a cabo, en gran medida, mediante la dote y los sistemas de herencia, esto es, por cauces relacionados con la familia. Esta desempeñaba un papel de primera importancia en el mantenimiento de un orden social cuya jerarquía parece depender, entre otros principios, del respeto hacia los mayores y los antepasados ${ }^{7}$.

5 J. Muriel, Cultura femenina Novohispana, México, UNAM, 2000. Véase también A. LAVRIN, Historia de las mujeres latinoamericanas, México, Siglo XXI, 1994.

${ }^{6}$ MURIEL, ob. cit., p. 9.

7 Véase James CASEY, Historia de la familia, Valencia, 1983, cap. 2.

Hispania Sacra, Missionalia hispanica, 58

117, enero-junio 2006, 329-353, ISSN: 0018-215-X 
Por esto - y mucho más que no señalo, ya que no viene al caso ${ }^{8}$ - , la familia gozó de una importancia singular durante la época moderna: es la célula básica de la sociedad, y la constitución de ésta, incluida su naturaleza política, es una proyección analógica de la relación familiar. Así lo hicieron ver constantemente los tratadistas de la época. Esta conclusión de la filosofía perenne se percibe con claridad en las obras del momento: la familia se entiende como el pilar más importante del Estado Moderno o, si se prefiere, el Estado como una suma de familias, correspondiendo a la autoridad del monarca su justo gobierno como al cabeza de familia el del grupo doméstico.

Así lo entendía Tomás Moro en Utopía $a^{9}$, llegando incluso a considerar el conjunto de la república como una familia a gran escala. Jean Bodin ${ }^{10}$ recoge la misma idea. Para el magistrado francés, de igual manera que «la administración doméstica es el recto gobierno de varias personas y de lo que les es propio, bajo la obediencia de un cabeza de familia», la «República es un recto gobierno de varias familias, y de lo que les es común, con poder soberano». En este sentido, la familia «constituye la verdadera fuente y origen de toda república, así como su principal elemento (...) Al igual que la familia bien dirigida es la verdadera imagen de la república, y el poder doméstico es comparable al poder soberano, así, el recto gobierno de la casa es el verdadero modelo del gobierno de la república».

En España, y sin duda por influencia de Bodin, las ideas al respecto vienen a ser las mismas. Por ejemplo, según el licenciado Martín González de Cellorigo, la república «es un justo gobierno de muchas familias y de lo común a ellas con suprema autoridad» ${ }^{11}$. De ahí la importancia atribuida a la vida familiar, desde donde deben ponerse en marcha los remedios que logren la restauración de España y los territorios hispánicos, en una relación vertical familias-estado. Por esto Cellorigo exhortaba a la nobleza para que impusiera el cumplimiento de las leyes en el seno de sus propias familias, con lo cual darían ejemplo al resto del pueblo ${ }^{12}$.

Y protagonista de la vida familiar a lo largo y ancho de la historia ha sido, y sigue siendo, la mujer. A la vista de todos está el cambio radical que se ha producido en los últimos años en torno a su papel en la sociedad, muy distinto al de

8 Véase en M. A. Bel Bravo, La familia en la Historia, Madrid, Encuentro, 2000.

9 Con otro título apareció en Lovaina, 1516, y definitivamente en Basilea, 1518. Ed. P. Rodríguez Santidrián, Madrid, Alianza, 1988, p. 136.

${ }^{10}$ Los seis libros de la República, París, 1576. Ed. P. Bravo Gala, Madrid, Tecnos, 1985, caps. I-II, pp. 9-19.

11 Martín GonZÁLEZ de CELloRigo, Memorial de la política necesaria y útil restauración a la república de España y estados de ella, y del desempeño universal de estos reinos, Valladolid, 1600. Ed. José Luis Pérez de Ayala, Madrid, Instituto de Estudios Fiscales, 1991, p. 63.

12 Ibid., p. 99. 
centurias pasadas, de ahí el interés de los historiadores por desentrañar los pormenores de la actividad femenina en épocas anteriores, liberando el tema de tópicos y examinando a fondo las causas de una posible marginación, tratando de evitar en todo momento simplificaciones fáciles.

\section{MuJERES EN AMÉRICA}

Mucho se ha hablado y escrito sobre la participación del hombre, del caballo, incluso del perro en la conquista del Nuevo Mundo. Muy poco se ha escrito, no obstante, de la participación de la mujer, y de su importantísima labor en el descubrimiento, colonización y evangelización de las nuevas tierras. Este factor ha sido ignorado por muchos historiadores que han querido ver en la conquista de América un hecho exclusivamente masculino, sin darse cuenta de que en la mayor parte de las expediciones y asentamientos posteriores las mujeres jugaron un papel de primer orden.

En opinión de Juan Maura, «la única razón de excluir a las mujeres en el panorama general de la conquista tiene una relación directa con la Leyenda Negra. El querer presentar a los españoles como un puñado de hombres cuyo último fin era saquear a los indígenas de todas sus riquezas, especialmente su oro, para marcharse una vez destruidas las culturas conquistadas, no dejaba cabida a la imagen de la mujer» ${ }^{13}$.

Entre las que viajan a América, las hay que marchan únicamente por acompañar a sus maridos y las hay inquietas y emprendedoras como aquellas que, entendiendo el importantísimo papel de la mujer educadora, van a servir de maestras a las niñas indias, mestizas y criollas. Las hay también piadosas que dejan los tranquilos monasterios españoles y cruzan los mares para que las mujeres en aquellas tierras puedan también dedicarse a Dios.

Damas de cultura y alta posición social, hijas de padres pobres pero hijosdalgos, campesinas, mujeres de clase baja, prostitutas, todas van en las mismas embarcaciones. Unas y otras, según lo que han sido y lo que quieren hacer de sus vidas, construyen con su trabajo, con su inteligencia, con su ambición, con su generosidad y con su sangre la Nueva España. Algunas llegan con los conquistadores, pero la gran mayoría cuando el imperio azteca ya ha desaparecido, cuando la violencia inicial de la conquista y sus secuelas van pasando para dar lugar a la consolidación de un vasto reino, al establecimien-

13 J. MAURA, «Mujeres hispanas en la conquista del Nuevo Mundo: a la vanguardia de los acontecimientos», en Revista de Estudios Hispánicos, año 22, 1995, p. 188. El autor critica la visión anglosajona de la conquista española de América, atribuyéndole una gran parte de la responsabilidad de la $L e$ yenda Negra que ha recaído sobre España.

Hispania Sacra, Missionalia hispanica, 58

117, enero-junio 2006, 329-353, ISSN: 0018-215-X 
to de una capital, en el mismo sitio donde se levantara antes la cabeza del imperio azteca.

Allí se emplazará una sociedad formada por los conquistadores supervivientes de la guerra y los primeros pobladores que llegan de la vieja España como savia nueva que va dando vida a las nacientes poblaciones. Y se mezclan la sangre y las culturas, y los que dominaron por las armas se imponen por el establecimiento de una forma de vida que se sustenta en los valores de la Europa Cristiana. Veamos algunos ejemplos.

En la biografía de Sor María Felipa de Jesús ${ }^{14}$, se puede apreciar claramente como esta mujer, hija de nobles indígenas y una de las primeras indias que ingresó en un convento, veía la conquista de América principalmente como un medio de la Providencia para llevar la gracia y la salvación a su pueblo. Esta visión está muy relacionada con las polémicas que se dieron desde el siglo XVI en torno a la salvación, la gracia y la fe, a las que se aludía antes:

«Considerando los medios con que la Divina Providencia le había traído a la religión cristiana, se transportaba toda en el Amor Divino. Discurría para sí que esta felicidad le había venido por haberse efectuado la conquista de estos reinos, por lo que daba gracias a Dios. Pero, al mismo tiempo atendiendo que según causas naturales dependían la gracia de ser cristiana de aquella contingencia, se llenaba de pavor y miedo, lloraba la infelicidad de los gentiles sus antepasados y se decía a sí misma: "Yo soy cristiana por la gracia de Dios y hará trescientos años, ¿qué eran mis abuelos, mis ascendientes? ¡Ay, de lo que me libró Dios!» En consecuencia de tanta estimación de la fe, eran los actos que hacía de esta virtud firmes, vivos y afectuosísimos y de aquí le venía la muy singular devoción con que rezaba el Credo y repasaba la doctrina cristiana todos los días, como es práctica en este convento, principiada desde su fundación».

Cuando se descubrieron los pueblos paganos de América muchos se preguntaron si la salvación estaba abierta a todos los hombres de buena voluntad; si estos individuos, que conocían la Ley natural a través de su razón y su moral, serían admitidos por Dios aunque nunca hubieran oído hablar de la religión cristiana. Para el protestantismo, el hombre había nacido tan corrompido por el pecado original que sólo la gracia de Dios podía redimirlo. Es verdad que la salvación es un don gratuito de Dios pero el hombre puede colaborar, o no, con sus acciones. La realidad histórica nos demuestra que esta visión, en el caso de algunas confesiones protestantes, condujo a una división de la humanidad entre predestinados a la salvación, aquellos que habían nacido en el seno del cristianismo; y no elegidos, entre los que se encontraban los pueblos paganos, los que nunca habían tenido la oportunidad de conocer la doctrina cristiana.

14 Véase Josefina MurIEL, ob. cit. en nota 1, p. 357. 
Aunque el concilio de Trento afirmó que la salvación es fruto tanto de la gracia divina como de las acciones libres de los hombres, reconoció que la fe era un elemento imprescindible para acceder a la salvación. Esta fue la doctrina que se enseñó a los indios convertidos; no es de extrañar que sor María Felipa imaginase, espantada, cuál habría sido su destino de haber nacido cuatro siglos atrás, antes de la llegada de los españoles; y se sintiera especialmente beneficiada por la Providencia gracias a la Conquista de América ${ }^{15}$.

Es conveniente indicar en este punto algunos ejemplos en relación con lo anteriormente dicho:

De la «pobrecita india» Petronila de la Concepción, donada del Real Convento, «sábese muy bien que deseosa de vivir consagrada a Dios se huyó de la humilde casa de sus pobres padres, entrándose para ello en la primera canoa, que salió de su ciudad para la de México» ${ }^{16}$.

Francisca de San Miguel era, como Petronila, india de innumerables virtudes: «no solo el haber sido muy mortificada, muy humilde, muy ayunadora, muy penitente, sino el que Dios la dotó de espíritu de profecía». «Por india, por retirada a un convento, y por no cuidar de otra cosa que de ser santa, necesariamente se debe inferir su pobreza suma» ${ }^{17}$.

El caso de María de San Juan es bastante similar, salvo que en esta ocasión se trata no de una india, sino de una negra criolla de México que probablemente había sido esclava: «acompañe aquí a estas dos indias siervas de Dios una negra, de quien pudieron las que se preciaban de muy blancas aprender virtud». De hecho se decía de ella «haber sido un prodigioso epílogo de las virtudes sin excepción alguna, sobresaliendo entre todas el amor de Dios y un celo de que nadie le ofendiese ${ }^{18}$.

Por otra parte, el escrito de la madre Inés de la $\mathrm{Cruz}^{19}$, nos habla de la visión que tenía una monja española del siglo XVI, acerca de las tierras recién descubiertas de América. El texto recuerda mucho a un pasaje de la vida de Teresa de Jesús, en el que nos cuenta que, siendo niña, se escapó de su casa para morir mártir en tierras de moros. De manera parecida, sor Inés de la Cruz, mientras viajaba hacia América, se entusiasmaba con la idea de sacrificar su vida por Dios: para la religiosa española, América constituía una tierra pagana hostil, una misión de evangelización, la oportunidad de extender la fe

\footnotetext{
15 Ibid.

16 Parayso Occidental, Carlos de Sigüenza y Góngora, México, 1684, facsímil recientemente publicado por Condumex y la Facultad de Filosofía y Letras de la UNAM. Yo he trabajado el texto que existe en la Biblioteca Nacional de Madrid: BN R/110. pp. 171-172.

17 Ibid. p. 174.

18 Ibid. p. 176.

19 Vida de la Madre Juana Inés de la Cruz, religiosa profesa en el convento de San Jerónimo de la Ciudad Imperial de México. Carlos de Sigüenza, Paraíso Occidental. México, 1684. BN R/110. p. 132.
}

Hispania Sacra, Missionalia hispanica, 58

117, enero-junio 2006, 329-353, ISSN: 0018-215-X 
cristiana y ganar a esos pueblos para Cristo, aunque arriesgase su vida en ello:

«Cuando iba a la iglesia me quedaba elevada considerando en los Santos lo que habían padecido por Dios, y lo mucho que su Majestad los había amado, y no me podían quitar de junto a los altares, pidiendo a Dios fuese yo toda suya. Como vi a tanta gente por las calles preguntaba qué hacían: respondíanme, que ganando de comer; teníales gran lástima, y lloraba porque no se empleaban todos en servir a Dios».

«Llegados a México (la familia) me desconsolé viendo no había ocasión de ser mártir ni convento de descalzas ni de entrar luego monja, por venir mi padre pobre [...]. Supe que las monjas tenían mozas, y estuve haciendo grandes trazas para sin ser conocida entrar por criada de alguna, y mudarme el nombre, y no decir de dónde era, porque mis padres no me hallasen, y así podría estar sin jamás ver a nadie, y estaría humillada, y me tratarían muy mal pensando que era alguna mala mujer. Deseaba mucho me tuviesen en poco por tener qué ofrecer a Dios, no hallé traza para cumplir esto, porque no me fiaba de nadie, ni yo podía irme, porque no sabía las calles».

A través de estas vidas, consideradas ejemplares y admiradas por sus biógrafas se pueden estudiar las cualidades de la mujer más valoradas en esta época: la obediencia, la sujeción, la humildad y la modestia, aunque también se menciona la inteligencia y la firmeza de carácter. Parece que se les exigían numerosos sacrificios, en especial a las mujeres de clase media o baja: completa obediencia y sometimiento, primero a sus padres y luego a sus esposos; matrimonios concertados que podían resultar muy amargos e infelices y que ellas aceptaban, la mayoría de las veces, sin rechistar; resignación ante reproches y castigos injustos; muchos hijos; largas vigilias al cuidado de enfermos; mantenimiento de la economía familiar trabajando en pequeñas artesanías; todo ello sin olvidar el cuidado de la casa y las propias mortificaciones y ayunos de la religión. En este sentido, llama la atención el caso de Antonia de la Encarnación ${ }^{20}$, primero casada y después una vez que enviuda, monja, cuyo matrimonio en especial se describe como una «grave y pesada cruz», y su vida como un espectáculo de dolores y trabajos.

Sin embargo, estas mujeres casi nunca se rebelaron contra su situación; de alguna manera, veían en estos sacrificios una especie de heroísmo. Recibían los reveses de la fortuna y las imposiciones como pruebas que la Providencia les ponía en su camino para templar su fortaleza; de todas maneras ninguna se hubiera atrevido a cuestionar lo que creían que era la voluntad divina. Hay un ideal estoico de dominio de sí mismas, de serenidad y firmeza ante las desgracias y

${ }^{20}$ María de Jesús Alonso y Herrera, Crónica del Real Colegio de Santa Rosa de Viterbo de la ciudad de Santiago de Querétaro. Manuscrito, cit. Por Josefina MurIEL, véase nota 5, p. 24. 
un gran afán de sacrificarse por una causa suprema: honrar a un Dios que dio su vida por la humanidad, sacar adelante una familia o un convento. Por otra parte, casi todas parecen aceptar la imagen que se tenía de cada sexo en la época: las letras eran un oficio «superior a su sexo» ${ }^{21}$; y si una mujer destaca por su valentía o firmeza de carácter, se explicaba por su espíritu «casi viril» ${ }^{22}$. Sin embargo, la educación, como veremos, tuvo suma importancia.

\section{LA EDUCACIÓN}

Con respecto a la actividad educativa, es preciso señalar que para la Iglesia educar a las mujeres fue la forma más fácil de cristianizar generaciones enteras, y los documentos ofrecen bastantes datos acerca de la educación de las mujeres. Las niñas eran educadas en la casa por sus propias madres o ingresaban en conventos como educandas, al cargo de monjas maestras. Valgan ejemplos como los de Sor Rosa de Loreto y su hermana, que, «al abrigo de la madre, fueron bien enseñadas en los misterios de nuestra santa fe y cristiana educación, empero como el padre deseaba dar a sus hijas mayores adelantamientos en la buena política y piedad cristiana aprovechándose de sus facultades, puso sus diligencias para que fuesen ambas admitidas en calidad de niñas, en el convento de la Concepción de esta ciudad, haciendo entrega de ellas a una devota religiosa». Sus padres, caciques y principales de su pueblo, «eran indios bien instruidos y temerosos de Dios, devotos y de competente discreción y así lograron sus hijos la oportunidad de una buena educación» ${ }^{23}$.

\section{También podemos citar el caso de Sor Antonia Pérez de los Santos:}

«Sus padres se llamaron don Lázaro Pérez de los Santos y doña Nicolasa de la Concepción, ambos caciques y nobles entre los de su nación y entre los cuales mismos fueron muy estimados, por sus cristianos procedimientos y aunque de ellos no hubiera otro testimonio de su buen juicio y piadosas costumbres, bastaría el que dio la hija cuando se presentó a la pretensión de ser admitida al santo hábito, pues desde luego se reconoció el cuidado y desvelo con que había sido instruida en la casa de sus padres, porque aunque ella era naturalmente de competentes potencias para aprovecharse de la buena educación y de una inclinación innata a todo lo bueno, todas estas prendas se hubieran quedado baldías y sin fruto, si no hubieran tenido cultivo como se queda la buena tierra sin los trabajos del labrador» 24 .

\footnotetext{
21 J. MURIEL, ob. cit., p. 48.

22 Ibid.

23 Véase J. Muriel, nota 1, p. 161 y ss.

${ }^{24}$ Ibid. p. 107.
}

Hispania Sacra, Missionalia hispanica, 58

117, enero-junio 2006, 329-353, ISSN: 0018-215-X 
Es igualmente ilustrativa la historia de Sor María Felipa de Jesús, de cuyos padres se dice que «ambos no sólo por sí sino también por maestras idóneas procuraron el que quedase bien instruida en la doctrina cristiana y buenas costumbres». «Los padres de María Felipa fueron muy estimados en toda aquella provincia, por su honradez y cristianos procederes, pues juntándose en sus ascendientes y ellos la nobleza y distinción entre los demás de su nación, pudieron ser bien instruidos en la política y religión y así dar a la hija buena doctrina y ejemplo» ${ }^{25}$.

Finalmente podemos señalar el caso de Sor Apolonia de la Santísima Trinidad: «Sus padres fueron indios caciques y principales como se colige de la bella educación que trajo su hija a la religión, fueron buenos cristianos y de muchos alcances, pues desde luego penetraron las obligaciones de criar bien a sus hijos» ${ }^{26}$.

La educación femenina giraba en torno a la iniciación en los asuntos religiosos, aunque también se las enseñaba a leer y a escribir y a desempeñar «las tareas de su sexo para mayor provecho de sus familias». En este sentido, acerca de Sor Rosa, india cacique, "se infiere con evidencia, el desvelo con que fue criada e instruida, porque vino muy bien inteligenciada en las cosas de nuestra religión y bien ejercitada en ejercicios de piedad y devoción. A este aprovechamiento, que debe ser el primero que produzca una buena educación, se añadió lo bien impuesta que estaba en los ministerios mujeriles, pues lavaba y labraba con primor, sin que la faltase el conocimiento, inteligencia de todo aquello en que para lo temporal pudiese ser útil al convento» ${ }^{27}$.

La cultura de algunas de estas mujeres debió ser profunda ${ }^{28}$, pues varias utilizan un estilo cuidado, con amplios conocimientos de la lengua latina así como de la Biblia. También son dignas de mencionarse las habilidades poéticas. Sin embargo, en ninguna biografía de las que he podido consultar se resaltan esas cualidades culturales.

Baste citar como ejemplo el caso de la Venerable Sor Petra de San Francisco, que «frecuentaba [...] los Santos Sacramentos, gustaba mucho de la lección de libros santos, continuamente ayunaba y practicaba otras penalidades para macerar su carne, porque no se rebelase contra el espíritu». Su padre y su madre, «como buenos cristianos entendieron bien las obligaciones con que estaban ligados siendo padres, de dar buena educación a sus hijos y como lo entendieron lo practicaron ${ }^{29}$.

25 Ibid. pp. 297 y ss.

26 Ibid. p. 205.

27 Ibid. pp. 139 y ss.

28 Véase, por ejemplo, la Crónica escrita por la Reverenda Madre María Bárbara de la Concepción, fundadora de los conventos del Dulce Nombre de Jesús de Querétaro y de Jesús María y José de Valladolid (Morelia) en 1805. Manuscrito ACJMJ.

29 J. MuRIEL, nota 1, pp. 75 y ss. 
Una vez que habían crecido, su actividad social giraba en torno a dos compromisos: en primer lugar con Dios, llevando una vida recogida para honrarle con oraciones y ayunos; y después «con la República», de acuerdo con el honor y la posición social de sus familias, que en algunos casos les imponía una vida «urbana y sociable». No faltan las quejas de las madres con respecto a esta obligada representación de sus hijas «en la gran feria de la sociedad», pues no pensaban más que en exhibirse en «hacerse conocer y celebrar» ${ }^{30}$.

Dentro de la familia, el papel de la mujer era el de «matrona»: encargada de la educación de sus hijos y de la dirección de la casa. Teniendo en cuenta que en esta época las relaciones familiares no son exclusivamente de parentesco, la dirección y el cuidado abarcaba también a los sirvientes. Pero, empecemos por el principio.

\section{LOS CENTROS EDUCATIVOS}

Los primeros misioneros que llegaron a la Nueva España, consideraron que para hacer una evangelización eficaz de ese mundo, que aceptaba los sacrificios humanos, antropófago e idólatra, era necesario ir más allá de prédicas catequísticas. Lo importante era la educación, la construcción de una nueva sociedad de hombres y mujeres que aceptaran la civilización occidental, para que con ello tuvieran una vida mejor en lo material y acorde con un nuevo concepto de sí mismos, de la sociedad y del Estado. En lo referente a nuestro tema, fueron los franciscanos los pioneros en la enseñanza a las mujeres indias, destacándose fray Toribio de Benavente Motolinía quien con la ayuda de fray Luis de Fuensalida, fundaron un primer colegio de niñas indias de América en el palacio de Netzahualcoyotzin, provincia del Santo Evangelio ${ }^{31}$. Este local que los franciscanos habían usado como convento desde el principio, fue cedido para el colegio cuando ellos pasaron a uno nuevo en $1528^{32}$.

El primer colegio era, según Zumárraga, «una casa muy principal con amplio alojamiento y servicio para más de cuatrocientas doncellas; tenía sala de labor e iglesia propia, en la cual los frailes sin estar dentro ni verlas les dicen Misa y les predican e informan en las cosas de nuestra santa fe católica» ${ }^{33}$.

\footnotetext{
${ }^{30}$ Ob. cit., en nota 5 , pp. 44 y ss.

31 La custodia de México se llamó provincia del Santo Evangelio hasta 1535.

32 Fray T. DE Benavente Motolinía, Memoriales, UNAM, Instituto de Investigaciones históricas, México, 1971, doc. XIV.

33 Fray Juan DE ZumÁrRAGA, «Carta del electo obispo de México, 27 de agosto de 1529», en Documentos inéditos relativos al descubrimiento y Conquista... sacados de los archivos del reino y muy especialmente del de Indias, Imprenta José María Pérez, Madrid, 1870, 1. a serie, tomo XIII, pp. 133134.

Hispania Sacra, Missionalia hispanica, 58

117, enero-junio 2006, 329-353, ISSN: 0018-215-X
} 
Cortés, en sus ordenanzas de 1524, se había obligado, como obligaba también a todos los encomenderos, a ocuparse de la educación indígena en sus encomiendas. En este sentido, dispuso la ayuda necesaria para la «sustentación e industria» del colegio. Por esto Herrera en sus Décadas dice que fue Hernán Cortés quien hizo el «Monasterio de las niñas». Y existe una Real Cédula en la que la emperatriz menciona un Monasterio hecho por Cortés, en el cual estaban ya en 1529 las hijas de Moctezuma ${ }^{34}$.

Como es sabido, la emperatriz Isabel se involucró personalmente en el tema educativo ${ }^{35}$, buscando y enviando maestras a la Nueva España. Lo hizo dando generosamente su tiempo y su hacienda para solucionar los innumerables problemas que el proyecto presentaba. El fundamental fue encontrar a las maestras idóneas, convencerlas de marchar para la misión educativa con las indígenas y hacerlas romper los lazos que las unían a sus familias o instituciones. Para ello fue necesario persuadirlas de que se trataba de una obra en servicio de Dios y de la Corona. Para que viajasen sin temor, doña Isabel les ofreció su cuidado y apoyo económico. Esta actividad desplegada por la reina nos permite asegurar su interés por las niñas indias.

Para formar lo que se llamó «Misión Imperial», la reina encomendó al franciscano Antonio de la Cruz que le buscase en Salamanca algunas religiosas de buena vida y ejemplo, que quisieran ir libre y voluntariamente a la provincia de la Nueva España a «industriar y poner en religión a las niñas». Entre las mujeres que aceptaron estuvo Elena Medrano, terciaria franciscana, profesa en el convento de Santa Isabel de Salamanca, que vivía emparedada en San Juan de Barbados. Iría acompañada de su sobrina, terciaria también. Igualmente, aceptaron ir otras terciarias como Juana Gra y Catalina Flores ${ }^{36}$. Del monasterio de Madrigal fueron otras dos beatas y una mujer casada que sabía «muy bien leer y la doctrina cristiana».

Conforme al deseo de la reina, estas mujeres salieron de Salamanca rumbo a Sevilla, de donde habían de partir hacia la Nueva España. Antes de embarcar, tres de ellas se arrepintieron «temerosas de cruzar el mar océano» ${ }^{37}$. Suplieron a las tres desertoras las terciarias sevillanas Ana de Mesa, Luisa de San Francisco con una «niña» y una criada ${ }^{38}$. También se preocupó la emperatriz de que las nuevas maestras dispusieran del material necesario para sus clases, que les hizo

\footnotetext{
34 A.G.I., Audiencia de México 1088-I, Reales Ordenes, Real cédula dada en Madrid el 4 de diciembre de 1529 a los Oydores de la Audiencia y Cancillería Real de la Nueva España.

35 ZUMÁRRAGA, ob. cit., pp. 133-134.

36 A.G.I, Audiencia México 1088-I, Reales Órdenes, Reales Cédulas a las devotas religiosas Juana Gra y Elena Medrano beatas emparedadas en San Juan de Barbados, Madrid, 14 de enero de 1530.

37 A.G.I., Audiencia México 1088-I, Reales Órdenes al Guardián del Cristo de San Francisco de Sevilla y Real Cédula a nuestros oficiales de la Nueva España, 25 de febrero de 1530.

38 Ibid.
} 
enviar por medio de Juan de Sámano: «trescientas cartillas de la Doctrina Cristiana encuadernadas en pergamino, para que las lleven las dichas beatas para mostrar a las indias» ${ }^{39}$. El 15 de agosto de 1530 , las seis beatas embarcaban en Sanlúcar rumbo a América ${ }^{40}$, donde llegaron a finales de noviembre.

La reina ordenó la instalación de este colegio diciendo «es mi voluntad que en la ciudad de México se dé el sitio más conveniente para el colegio que piden los franciscanos», puesto que la intervención de Zumárraga había sido decisiva. A él se encomienda la erección de este colegio, que sería llamado el de «La Madre de Dios» y que se instalaría en la que fuera casa de Gaspar de Ávila, añadiéndosele después dos casas más. Ocho meses más tarde el colegio comenzó a funcionar con doscientas alumnas, número que poco a poco fue aumentando, hasta contar con más de cuatrocientas.

Con el mismo fin de educar a las niñas indígenas en internados, los frailes habían buscado mujeres españolas. Para el de Texcoco hallaron a Catalina Bustamante, que era terciaria franciscana ${ }^{41}$. Esta mujer y su marido Diego Tinoco, extremeños, habían llegado a santo Domingo el año 1514 con sus hijas María y Francisca y sus sobrinas Juana y María ${ }^{42}$. Es interesante el hecho de que fuera terciaria, para empezar a conocer el papel que desempeñaron las terceras órdenes en la vida colonial.

Enseñó a las indígenas un nuevo modo de vivir, distinto al suyo en sus bases culturales, en el cual se comprendían desde la lengua castellana, la manera de vestir, la realización de nuevas labores femeninas, hasta las virtudes humanas y cristianas. Les enseñó a memorizar el Catecismo que los frailes explicaban, a entonar el canto llano y rezar las Horas de Nuestra Señora. Educó a las solteras para que se casaran con muchachos educados por los franciscanos, de acuerdo con el matrimonio cristiano monógamo e indisoluble, ayudándolas a formarse una nueva conciencia de su calidad de personas, para que no se dejaran regalar o vender por sus padres a los poderosos españoles o a los caciques indígenas.

Catalina de Bustamante, fundadora del primer colegio para niñas indígenas, fue consciente de la magnitud de la obra educacional, cruzó nuevamente el mar y se presentó ante el Consejo de Indias de 1535 exponiendo la insatisfecha necesidad de maestras, y pidió ayuda a la emperatriz. Dice que: «ha trabajado y padecido mucho en administrar y tener a cargo muchas doncellas hijas de los

\footnotetext{
39 A.G.I. Audiencia México 1088-I, Reales Órdenes, Real Cédula a los oficiales de la ciudad de Sevilla en la Casa de Contratación

40 Fray Ángel ORTEGA, Archivo Iberoamericano, «Las primeras maestras y sus colegios-escuelas de niñas en México (1530-1535), Madrid, 1929.

41 T. Motolinía, ob. cit., doc. XIV.

42 A.G.I., leg. 5536, libro I, fol. 368.
}

Hispania Sacra, Missionalia hispanica, 58

117, enero-junio 2006, 329-353, ISSN: 0018-215-X 
pobladores de la tierra como las naturales», que siendo el trabajo abrumador «ella sola no puede sufrirlo» por lo que pide le permitan llevar a la Nueva España más maestras bajo el patrocinio de la Corona.

Escogió para maestras a tres correligionarias de Sevilla: Catalina de Muela, Isabel Pérez y Francisca de Velazco. El camino de las misiones educativas ya estaba abierto. La reina accedió luego a su petición y tras recomendar a sus oficiales de la contratación que investigaran la buena vida y costumbre de las tres terciarias propuestas, les pagaron el pasaje a la Nueva España, junto con el de Catalina de Bustamante ${ }^{43}$. Se embarcaron hacia el 3 de octubre de 1535 en la nao del maestre Pedro Hernández Xerez ${ }^{44}$.

Una de las maestras enviadas por la emperatriz, trabajó en Texcoco con Catalina de Bustamante, dos fueron a Huejotzingo. Juana Velázquez, que regresó a España, daba un informe a la reina diciéndole en nombre propio y de sus compañeras que todas se habían ocupado «de la enseñanza de las niñas hijas de los caciques y principales de la tierra» ${ }^{45}$. Ana de Mesto trabajó allí trece años, regresando a Sevilla en 1544. Luisa de San Francisco en 1544 aún estaba en el colegio de la Madre de Dios, al lado de Zumárraga. Elena de Medrano nunca regresó a España y, además de ser maestra de indígenas durante muchos años, fundó el primer convento de monjas de América, La Concepción, el llamado por Carlos de Sigüenza y Góngora Parayso occidental en contraposición al paraíso perdido de nuestros primeros padres ${ }^{46}$.

La educación comprendía lo que era la preparación para ser señora de su casa, esposa y madre, lo cual se denominaba «regir la casa» ${ }^{47}$. A esto se sumó la enseñanza de las artesanías femeninas que las mujeres españolas practicaban. Las indígenas sabían hilar el algodón y el ixtle, pero no el lino, ni la lana. Hubo una orden de la reina a la Segunda Audiencia mandando que las mujeres de la Nueva España hilaran la lana ${ }^{48}$. Para enseñar todo esto las maestras trajeron los elementos necesarios tales como hilos, agujas, tijeras, etc., y con todo ello se fue enriqueciendo la artesanía nativa produciéndose un hermoso mestizaje artesanal que aún se halla vivo en toda la nación. Preparar a las mujeres para estas labores se consideró parte importantísima en la educación, pues con ello ampliaban el medio de sostenimiento para ellas y sus familias. Por esto en los edi-

43 A.G.I., Contratación 4676, Real Cédula a los oficiales de la Casa de Contratación, Madrid, 16 de junio de 1535 .

44 A.G.I., Contratación 4676, data del 3 de octubre de 1535.

45 L. Gómez Canedo, Archivos Históricos de México, Madrid, Tavera, 1997, p. 106.

46 Véase nota 16.

47 Recopilación de las Leyes de los reinos de las Indias, facsimilar de la cuarta impresión de Madrid, 1791, Consejo de la Hispanidad, Madrid, 1943, libro I, tit. III, ley XIX.

48 A. DE HERRERA, Historia General de los hechos de los castellanos en las islas y tierra firme del mar océano, Editorial Guaranda, Asunción del Paraguay, década IV, tomo V, libro VII, p. 354. Véase también E. LuQue y J. SARAnYANA, La Iglesia Católica y América, Madrid, 1992. 
ficios de todas las instituciones femeninas hubo siempre como elemento esencial, una sala de labores.

Sobre su propósito básico que fue la evangelización en su amplio sentido, Zumárraga señala en 1537 que la actividad de las maestras enviadas por la emperatriz, había tenido espléndidos resultados: «porque las inditas... después de haber aprendido bien los rudimentos de nuestra Santa Fe, vienen a relatar después con grandísimo provecho a sus padres y deudos, lo que les han enseñado» ${ }^{49}$. Queda bien claro en los textos biográficos que hemos reseñado en las primeras páginas de este estudio.

Además, lo que estas mujeres aprendieron — núcleo central de nuestro trabajo- , traspasó el ámbito familiar porque empezaron a salir a enseñar a otras indígenas, según dice Motolinía ${ }^{50}$. Y Mendieta afirma que las indias criadas en los colegios ayudaron a los frailes en la evangelización ${ }^{51}$, cuestión que se reconoce en la real cédula de 1536. Se trataba de la enseñanza directa de algunas que se denominaron «beatas», según Motolinía y Sahagún, y también de las niñas que, acompañadas de indias viejas o porteras, salían de los colegios «a enseñar e ansi en los patios de las iglesias, como en las casas de las señoras principales, y a muchos convertían a se baptisar y ser devotas cristianas y limosneras y siempre han ayudado en la doctrina las mujeres, aunque no discurriendo» ${ }^{52}$.

Motolinía dice que «después de casadas aquellas colegialas antes que se cargasen con el cuidado de los hijos, proseguían los santos ejercicios», reuniéndose en las iglesias a repetir la doctrina y a rezar el Oficio de Nuestra Señora y el Romano, como lo habían aprendido en sus colegios. Por esto afirma que al colegio de la Madre de Dios de México, acudían los indios para oír a sus hijas cantar las Horas. Mendieta señala: «De las mozas criadas en los monasterios hubo muchos ejemplos de virtud y honestidad por donde se le conoció no haber sido infructuosa esta buena doctrina ${ }^{53}$. La conclusión obvia es que estas mujeres fueron las grandes artífices de la renovación indígena porque colaboraron sustancialmente al mestizaje cultural de México, así como de gran parte de Hispanoamérica.

\footnotetext{
49 J. García Icazbalceta, Colección de documentos para la Historia de México, doc. 17, pp. 306-308. Carta al Capítulo General de Tolosa, 1532.

${ }^{50}$ Motolinía, ob. cit., cap. LXII, p. 193.

51 Fray Jerónimo MENDIETA, Historia Eclesiástica Indiana, tomo II, cap. XXIX, p. 482.

52 Motolinía, ob. cit., pp. 192-193.

53 MendiETA, ob. cit., tomo II, cap. LII, pp. 171-173 y tomo III, cap. XIV, p. 73.

Hispania Sacra, Missionalia hispanica, 58

117, enero-junio 2006, 329-353, ISSN: 0018-215-X
} 


\section{LOS CONVENTOS}

Las primeras noticias que nos llegan acerca del inicio de los conventos femeninos en América corresponden a la Nueva España, ya que desde 1525 se elevaron a la Corona peticiones para el envío de religiosas, con objeto de atender a las mujeres indias y mestizas que poblaban estos territorios, pero recibieron el rechazo de las autoridades, al considerar que era demasiado pronto para permitir el paso de este tipo de mujeres. Como la instalación de conventos estaba sujeta a la autorización real, por el Real Patronato, ésta fue concedida sólo cuando la expansión española en América hubo crecido considerablemente.

No obstante la insistencia de los obispos, la Corona mantuvo su negativa hasta 1538. Sólo hacia 1540 se produjo la aceptación y de inmediato, en pocos años, tuvo lugar la instalación de varias casas de religiosas. Sin embargo, antes de que éstas tuvieran pleno asentamiento se establecieron los llamados «beaterios», que eran grupos de mujeres piadosas que decidían hacer vida en común para perfeccionar su religiosidad y servir al prójimo, ya que daban albergue y educación a niñas huérfanas, mestizas o españolas. Este tipo de establecimientos estuvo propiciado por particulares, muchas veces esposos, preocupados por la suerte de la mujer, ya fuesen niñas, viudas, solteras e, inclusive, en los casos de mujeres de vida licenciosa para llevarlas al arrepentimiento en las casas de «divorciadas» 0 «arrepentidas».

La primera labor que se quiso confiar a las religiosas fue la educación, como se ha señalado, aunque ésta empezó a ser desempeñada por Terciarias franciscanas, las cuales formaban parte de una cofradía, y mujeres laicas de probada honestidad y vida cristiana, cuya obra se inició desde 1530, con seis de estas «beatas» o «maestras amigas». Sin embargo, existió una cierta oposición indígena a los colegios. Zumárraga lo explicó diciendo que «los jóvenes indios educados en los conventos por los frailes rehusaban de casar con las doctrinadas en las cosas de las niñas, alegando que las criaban ociosas y a los maridos los tenían en poco, ni los querían servir; según la costumbre suya que ellas mantiene a ellos, por haber sido criadas y doctrinadas de mujer de Castilla» ${ }^{54}$.

Los padres de familia por su parte, no aceptaban de buena gana que sus hijas estuvieran en los colegios debido a la libertad que allí tenían para salir, pues estaban acostumbrados a tenerlas en total encerramiento. Su descontento lo manifestaron boicoteando económicamente a las instituciones al retirar el mantenimiento que estaban obligados a dar a las hijas allí internadas.

En torno a 1549 empezó a considerarse que educar a las niñas en colegios internados, no era ya indispensable para la evangelización de las nuevas generaciones, porque, según Motolinía, como sus padres eran ya cristianos

${ }^{54}$ MotoliníA, ob. cit., cap. LXII, p. 139. 
ellos les enseñaban, siendo además un hecho generalizado el que las que habían entrado grandecitas a las escuelas, ya de casadas se dedicaban a enseñar a otras mujeres.

En los primeros tiempos es posible que no se supiese cómo orientar la evangelización de la mujer y por esto se estableció en Texcoco, en 1529, un colegiobeaterio con clausura para mujeres indias de la nobleza, viudas y doncellas, donde beatas franciscanas las iniciaran en la religión y la piedad. Por el tipo de formación que se les ofreció, se les quería preparar al matrimonio, ya que se dudaba que pudieran ser aptas para la vida monacal. Se intentó, asimismo, que luego se convirtieran en catequistas dichas educandas, pero esto no duró más allá de diez años, porque al avanzar la cristianización de los varones, su acción resultaba secundaria.

La actitud frente a la mujer india fue confusa, pues por un lado se le consideró muy sensual, pero por otro se creyó que al existir sacerdotisas en los cultos americanos, donde se les exigía guardar la virginidad, podía ser éste un buen antecedente para el monacato. Sin embargo, al considerarse al indio americano como permanentemente en minoría de edad, se decidió que ni los hombres ni las mujeres podían alcanzar los más altos grados conventuales y quedaron relegados sólo a la condición de legos o donados. No obstante, en México fue famosa por sus virtudes una indígena: Juana de San Jerónimo, y regularmente se la menciona como madre, aunque nunca pudo profesar.

Naturalmente, una igual o mayor atención se quiso brindar a las españolas pobres y mestizas, a través de colegios-recogimientos, dependientes de cabildos, cofradías o particulares, dirigidos por una rectora. Su creación fue sancionada por las leyes de Indias y debían ser visitadas anualmente por el virrey o los oidores. En 1530 se estableció el primero, en Santo Domingo, a cargo de beatas y el segundo recogimiento fue en 1548, de la Cofradía del Santísimo Sacramento «Colegios de Niñas o La Caridad» en México, para «... recogimiento de ninas, doncellas de todas edades, españolas y mestizas que andan perdidas por la tierra».

En este sentido, es preciso seguir consultando la edición facsímil de la Crónica del Convento de Corpus Christi, que publicó en su día la Dra. Josefina Muriel $^{55}$, cuyos textos, aunque sin estudio crítico, como señalábamos en la Introducción a este trabajo, arrojan algunas valoraciones interesantes sobre lo que pensaban las monjas, indias caciques, acerca de la conquista española, por haberles traído la fe cristiana. Es un testimonio importante, directo.

En principio, esta vida parece dominada por la mortificación y la humildad. Todas se conciben a sí mismas como instrumentos de la Providencia, las más

55 Las indias caciques de Corpus Christi, México, Universidad Nacional Autónoma, 2001.

Hispania Sacra, Missionalia hispanica, 58

117, enero-junio 2006, 329-353, ISSN: 0018-215-X 
inútiles e indignas del convento, ni siquiera merecedoras de la Gracia y Misericordia que Dios derramó en ellas. María Bárbara de la Concepción ${ }^{56}$ da por sentado que su destino es el Purgatorio. Hay que tener en cuenta que en la época esta disposición de humildad es condición indispensable para la vida entregada, tanto en mujeres como en varones.

También llama la atención el ascetismo: hay un marcado desprecio por los placeres de este mundo, deseo de llevar una vida recogida y pobre, evitar cualquier distracción que interrumpa su unión con Dios. Se habla mucho de contricción y sometimiento a una autoridad superior. Por ejemplo, muchas de ellas afirman escribir sus crónicas por obediencia, a veces «forzando la voluntad» ${ }^{57}$; ninguna se atreve a reconocer abiertamente que le produce algún placer escribir; tampoco que tenga ninguna pretensión literaria ya que la única aspiración es la gloria de Dios, aunque el estilo cuidado, la búsqueda de la belleza o la emoción lo desmientan.

En estos conventos las mujeres encontraban espacio para tomar sus propias determinaciones y seguir un modelo de heroísmo. Eran ellas, habitualmente, las que decidían ingresar en el convento, movidas por una vocación sentida desde niñas. Eran ellas las que tomaban la iniciativa para nuevas fundaciones, teniendo así parte activa en la cristianización de América, convenciendo incluso a confesores y nobles para que ayudaran a la empresa, buscando apoyos donde fuera menester, trabajando incansablemente para mantener las nuevas comunidades. En este sentido, mediado el siglo XVII, la madre María Ignacia Azlor y Echevers viajó a España y logró convencer a Felipe IV $^{58}$ para levantar un nuevo convento en América, con el argumento de que quería rendir un servicio a su Patria de nacimiento y que sería una reparación justa para la Nueva España, ya que el oro que circulaba en la Corte procedía de sus minas.

También se da el caso de comunidades que se forman a partir de una mujer viuda que quería llevar vida retirada junto a algunas de sus hijas, doncellas o viudas como ella, mandando construir pequeñas dependencias para cada una en su propia casa.

La anteriormente mencionada Venerable Madre Petra ${ }^{59}$ «buscó desde muy temprana edad quien la gobernase y dirigiese en el camino espiritual, conociendo muy en breve la necesidad de guía para no tropezar o embarazarse en el ejercicio de las santas virtudes y le deparó Dios un ministro cual podía desearlo,

56 Véase nota 14.

57 Ibid.

58 Fundadora del convento de Nuestra Señora del Pilar, vulgarmente conocido como «La Enseñanza». Relación histórica de la fundación de este convento de Nuestra Señora del Pilar, Compañía de María, llamada vulgarmente La Enseñanza. Escrita por un grupo de monjas del mismo, en 1793, cit. por J. MURIEL. Véase nota 5.

59 Véase nota 30. 
fue éste el padre fray Juan Fernández de Cejudo, religioso recoleto docto y muy virtuoso, morador de San Cosme, quien bien enterado de las buenas proporciones de Petra, puso su esmero para labrar aquel diamante, en que reconoció tan bellos fondos. Continuó éste gustoso la dirección hasta que la obediencia lo envió a Roma, a ciertos negocios, en donde murió en opinión de santidad».

Los padres de Sor Gertrudis del Señor San José ${ }^{60}$, caciques y principales de su pueblo, «criaron a la hija en el santo temor de Dios, instruyéndola en los misterios y verdades de nuestra religión. Estos cuidados, con el de tenerla recogida en casa excusándole malas compañías, produjeron buenos efectos en la niña, bien que éstos se debieron, por la mayor parte a su buen entendimiento, bella natura y santas inclinaciones».

Ante la noticia de la apertura de un nuevo convento en México para indias caciques, «se excitó en su corazón un ardiente deseo de ser religiosa, el que comunicó a sus padres y éstos gustosos lo aprobaron y apoyaron sus buenos pensamientos, considerando que con el logro de la elección de la hija no solamente la colocaban con la mayor honradez que podían desear, sino que también la consagraban a Dios para que ella siguiese mejorada la buena vida de que les había dado tantas pruebas».

El convento también les ofrecía la posibilidad de emplear la pluma, ya fuera llevando los asuntos básicos de la comunidad o escribiendo las Crónicas del convento: la mayoría de las mujeres aprendían a leer y escribir siendo niñas, pero en muchas ocasiones se les olvidaba por falta de uso. Llama la atención que las únicas crónicas escritas por mujeres sean exclusivamente obra de religiosas y que apenas sobrepasen el ámbito del convento.

La Venerable Madre Petra «hizose maestra de niñas y tomó con todo empeño este ejercicio, dándolas buena educación e instruyéndolas en todo lo demás, a que como tal estaba obligada. Tantas ocupaciones no resfriaron el buen espíritu de Petra, porque teniendo por felicidad el sustentarse del trabajo de sus (manos) y por ejercicio de sólida caridad el que participasen de él su madre y hermana, movían todas sus operaciones, el amor de Dios y de las virtudes».

Los escritos utilizados en este trabajo, en su mayor parte, no fueron redactados para publicarse. En muchas ocasiones se advierte un cierto afán literario, como dice la historiadora que recopiló los fragmentos, y se puede apreciar una especie de gusto en el relato de sus propias hazañas, para que quede constancia de ellas. También aprovechaban para desahogar los anhelos y sentimientos que las impulsaban; buscar la belleza y la emoción, o cuando menos, un uso cuidado del lenguaje. Asimismo, se habla de la participación de estas monjas en la-

60 Véase nota 1.pp. 221-223.

Hispania Sacra, Missionalia hispanica, 58

117, enero-junio 2006, 329-353, ISSN: 0018-215-X 
bores artísticas, como la talla de pequeños Niños Jesús, que ellas realizaban «con mucho primor».

Estos textos ofrecen bastantes detalles sobre la vida en comunidad de los conventos: el cariño que se tenían entre ellas, como se puede ver en las emotivas despedidas; la puesta en común de todos los bienes, el servicio y la asistencia mutua, el dolor al separarse del convento tras las exclaustraciones del siglo XIX; la admiración por las madres fundadoras o las hermanas ejemplares; los trabajos en el huerto o en la artesanía culinaria; las penurias pasadas en épocas de revueltas; la elección de la madre priora; las procesiones de la imagen del Niño Jesús por las celdas, etc.

Estas comunidades parecen ser muy respetadas por las autoridades que colaboran en su fundación y les otorgan protección; también por el pueblo que se comportaba generosamente a la hora de las limosnas para su manutención. Tanto crónicas como biografías, se escriben con propósito ejemplarizante. De alguna manera, estas monjas, con su espíritu de fortaleza, de misión y de sacrificio ofrecían un modelo de heroísmo en el que las mujeres podían participar, ser tenidas en cuenta por sus virtudes, por su esfuerzo en contribuir a la construcción del Reino de Dios en la tierra. Santa Teresa de Jesús, por ejemplo, es muy citada como modelo a seguir. Y es preciso no olvidar que los primeros mártires del cristianismo, que se sacrificaban por la causa de Dios, se consideraban héroes cristianos.

Sobre la Venerable Madre Magdalena de Jesús ${ }^{61}$ hay que decir que tuvo la suerte de tener «buenos y diligentes padres que atentos a la buena educación de sus hijos, le procuraron los mejores medios de que la lograsen». «Mereció la niña, de la Divina Providencia, la felicidad de unos buenos y cristianos padres y tales, que pudieran zanjarle con la primera educación, los primeros cimientos para la heroica santidad a que la tenía destinada».

Además de los textos reseñados, la gran cantidad de sermones panegíricos y biografías de mujeres escritas por varones durante el periodo colonial, muestran de forma evidente la primacía del valor religioso, pues de los que he podido ver, muchos se refieren a mujeres que destacaron por sus virtudes. También se detecta en dichos escritos el interés que los hombres tuvieron por sus vidas. Con frecuencia habíamos aceptado la idea de que en aquellos tiempos las mujeres ocupaban un lugar secundario y sin importancia, pero ahora esta teoría es insostenible. Sólo podemos decir que ocupaban un lugar diferente al que hoy tienen. Los escritores del Virreinato nos están demostrando con sus obras que valoraban la vida de esas mujeres como parte constitutiva de la sociedad. Sin ellas era imposible la estabilidad social y política de la Nueva España, porque eran las que marcaban el ritmo de la minúscula sociedad familiar, que a su vez hacía funcionar la sociedad en general.

61 Véase nota 1, p. 243. 
Y esto en todos los sentidos, porque las mujeres biografiadas, con sus vidas de caridad, desprecio de la riqueza, cuidado de los pobres, fundaciones de obras pías y todo tipo de trabajos asistenciales, vertebraban una sociedad en la que las diferencias eran cada vez más acusadas. Si no era posible lograr la unidad a través de la lengua o de la raza, porque eran miles las que existían en el territorio, ello sólo se podría lograr mediante la religión. Una mayor justicia social interesaba tanto a la Iglesia como al Estado y estas biografías de mujeres la fomentaban.

\section{LOS LIBROS}

En el México hispano las mujeres no entran en los Colegios Mayores ni en la Universidad, pero pueden instruirse por sí mismas leyendo. Sor Juana Inés de la Cruz describe lo que era ese esfuerzo de estudiar sola sin compañeros ni maestros, diciendo: «Leer y más leer, estudiar y más estudiar sin más maestros que los mismos libros. Ya se ve cuán duro es estudiar en aquellos caracteres sin alma, careciendo de la voz viva y explicación del maestro» ${ }^{62}$.

A la Nueva España llegan los libros autorizados, los que no contienen herejías contra la fe de los recién convertidos o las buenas costumbres de los cristianos viejos. Pero a hurtadillas entran otros tildados de vanos y profanos. Los documentos de registro de las naves, los inventarios de librerías y de obras confiscadas por la Inquisición, los catálogos de las bibliotecas de instituciones públicas y privadas que de aquellos tiempos conocemos, nos permiten saber que en la Nueva España se leían libros muy diversos, que se tenía un gran interés en las obras «vanas», como son los libros de caballerías: el Amadís de Gaula, La doncella Teodor, la Crónica de los nobles caballeros Tablante de Ricamonte y de Jofre, hijo de Donason, Flores y Blancaflor, Palmerín, la Historia del emperador Carlomagno y de los doce pares de Francia, etc.

Leían también La Celestina y El Lazarillo de Tormes. Se conocía y estudiaba con gran interés a los poetas griegos y latinos como Homero, Horacio, Virgilio, Ovidio y las comedias de Aristófanes traducidas al latín. Se leía a nuestros clásicos castellanos, como Cervantes: Novelas Ejemplares y el Quijote, Lope de Vega y Lope de Rueda. Circulaban los versos de Juan de Mena, las Églogas de Garcilaso. Tenían gran interés las colecciones de versos como el Jardín de flores, Floresta española, Vergel de flores divinas, el Cancionero de Montemayor y los romanceros. Muy populares fueron las Coplas de Jorge Manrique. Venían en las naves, destinados a libreros o a particulares, libros para la enseñanza de la retórica y la gramática y desde luego el Arte de la lengua de Nebrija. Tam-

62 Obras completas, México, Porrúa, 1975. p. 10.

Hispania Sacra, Missionalia hispanica, 58

117, enero-junio 2006, 329-353, ISSN: 0018-215-X 
poco faltaban los de enseñanza del latín como el llamado De elegantia lingua de Lorenzo Valla.

Se leía historia en obras tales como la Ystoria generis umani de Arias Montano, las obras de Xenofonte, la Historia de España de Mariana, y las crónicas como la del rey don Rodrigo al igual que las referentes a América de Gómara, Acosta, Torquemada, etc. No faltaba la Historia del Abencerraje y la hermosa Jarifa, así como Las guerras civiles de Granada de Ginés Pérez de Hita, y La Araucana de Alonso de Ercilla.

Las obras de carácter filosófico, teológico, religioso y moral fueron propagadas por los misioneros, maestros de colegios y universidades. Se leía y estudiaba la Biblia, Antiguo y Nuevo Testamentos, en la versión autorizada completa o partes de ella, pese a las prohibiciones que hubo por los peligros que el movimiento de la Reforma había introducido. Circulaban por todos lados las obras de los padres de la Iglesia como San Jerónimo, San Agustín, San Ambrosio, San Gregorio Nacianceno, Santo Tomás de Aquino, etc. Las vidas de los santos y santas, individuales o en colecciones, como el Flos sanctorum, eran leídas en familia. Las obras de los clásicos cristianos españoles como fray Luis de León, fray Luis de Granada, Santa Teresa, San Juan de la Cruz, el beato Juan de Ávila y las de la madre María de Jesús de Ágreda, María de la Antigua y los Libros de Horas se encontraban en las casas de las familias piadosas.

Saber leer permitía a las mujeres adquirir cultura según su interés personal. Puesto que ellas no tenían una vida activa fuera de su casa, disponían de tiempo para leer y de hecho lo hacían. Lope de Vega dice en una de sus obras: «Doncellas encerradas en su casa entre la labor y el libro». Se puede pensar que dentro de la vida de las mujeres, la lectura era una necesidad que llenaba el espíritu más que el trabajo manual. En la comedia del mexicano Alarcón, La prueba de las promesas, una hija dice a su padre: «Ya sabes, señor, que más me deleitan tus libros que mis labores». Y las citas de esas obras literarias que tienen sus raíces en la vida del pueblo son rica fuente de información del ambiente de una época.

Confesores y predicadores nos dicen que era común la lectura entre las mujeres, quejándose de la desmedida afición que tenían a leer novelas y comedias, y los versos del Renacimiento español lo confirman: "cuarenta veces dejará la media/como se ofrezca leer una comedia...».

Aunque no conocemos ningún texto que haya pertenecido a colegios de niñas indígenas, fuera de las cartillas de doctrina y alfabetización mencionadas, y por supuesto los catecismos pictográficos como el de fray Jacobo de Testera ${ }^{63}$,

63 M. LEÓN-PORTILla, Un catecismo náhuatl en imágenes, introducción, paleografía, traducción al castellano por..., Cartón y Papel de México, S.A. de C.V., México, 1979. 
quizás entre los libros ejemplares que debían leerse las niñas, se encontraba el popular Flos Sanctorum del que fray Juan de Rivas hizo tempranamente un resumen ${ }^{64}$.

\section{A MODO DE CONCLUSIÓN}

Los datos que tenemos nos confirman la puesta en marcha en el siglo XVI de dos tipos de centros educativos para las niñas indígenas: las escuelas elementales externas, como las fundadas en Yucatán por el franciscano Diego Martín, entre 1530 y 1569 y los recogimientos para niñas indias, con carácter de internado, como los promovidos por Zumárraga y encomendados a las beatas de la Tercera Orden de San Francisco, llegadas en 1530, y a las ocho mujeres seglares enviadas por la emperatriz Isabel en 1534. Las dificultades que encontraron estas educadoras seglares, hicieron desistir al primer obispo mexicano del proyecto y abogó por el paso a la Nueva España de las monjas concepcionistas, para que se hicieran cargo en su propio convento de la educación de las niñas indígenas, procedimiento usual entonces en toda Europa y muy extendido en los reinos hispanos.

Por otra parte, las obras impresas y documentos que he consultado proporcionan una preciosa información histórica acerca de la mujer en el aspecto familiar y conventual en los diferentes estratos sociales; la forma de vivir en el campo y en las ciudades; la dependencia de las mujeres consignada en las leyes, aunque a veces rota por ellas en tenaces enfrentamientos para elegir el tipo de vida que deseaban. Esos textos me han aportado datos muy valiosos sobre gobernantes y gobernados, pero sin duda para la relevancia del trabajo que hoy presento, lo más importante es que reflejan admirablemente la transmisión y, en su caso, la recepción personal de la fe cristiana por parte de cada una de las autoras, y su compromiso personal para difundirla.

Estos escritos, no sólo señalan la importancia de la fe como elemento central en la constitución de la Nueva España, sino que sus autoras se nos presentan como las principales transmisoras de esa fe, que implica, según ellas, una forma de vida pletórica de valores, recibidos a través de la familia e instituciones: colegios, conventos y beaterios. Digamos que en sus escritos aparece más detallado que en los masculinos el objetivo del proceso inculturador. ¿Qué objetivo?: primero hombres, después cristianos; pues los españoles y españolas que mar-

${ }^{64}$ F. J. DE MendietA, Historia eclesiástica indiana, Edición Joaquín García Icazbalceta, México, 1870, tomo III, cap. XLIV, pp. 212-215.

Hispania Sacra, Missionalia hispanica, 58

117, enero-junio 2006, 329-353, ISSN: 0018-215-X 
charon a Indias estaban convencidos, y supieron trasmitir esa idea básica del catolicismo, a saber que entre hombre y hombre no hay diferencia esencial, pues «la fe es el fundamento de toda perfección cristiana y que al paso que ésta crece y se radica más en el alma, se aumentan en ella misma, el escuadrón de las demás virtudes» ${ }^{65}$.

65 Véase nota 1, p. 355. 